\title{
An Assessment of Knowledge, Attitude and Practice towards Diabetic Retinopathy among General Practitioners of Tabuk City Fahad S. Alanazi ${ }^{1}$, Tariq H. Merghani ${ }^{1}$, Ala M. Alghthy ${ }^{1}$, Reem H. Alyami ${ }^{1}$ \\ ${ }^{1}$ College of medicine, Tabuk University, Tabuk City, Saudi Arabia Corresponding author: Fahad Alanazi; E-mail address: enezifahad@ hotmail.com, Mobile Number: 0966582137150
}

\begin{abstract}
Background: Diabetic retinopathy (DR) is the leading cause of blindness in the working population. Adherence to screening guideline will help in the prevention of blindness. General practitioners (GPs) are the 1st line in management of diabetic patients. This study aims to determine their knowledge, attitude and practice toward diabetic retinopathy and to identify factors that affect their practice. Material and method: We conducted a cross-sectional study among a comprehensive sample of the GPs who work at primary health care units of Tabuk city from July to December 2017. A validated self-administered questionnaire was used for data collection. Statistical analysis was performed by using Statistical Package for the Social science (SPSS) version 20. Results: A total of 87 general physicians completed the questionnaire (a response rate of 100\%). Only $24.1 \%$ of GPs could identify pregnancy as a risk factor. Only $43.7 \%$ and $28.7 \%$ were aware of retinal detachment and vitreous hemorrhage as complications of DR, respectively. Only $27.6 \%$ of the GPs referred type I diabetic patients to an ophthalmologist as per the guideline. The gender difference in referral pattern was found to be statistically significant $(\mathrm{p}=0.041)$. Major challenges that may prevent GPs from doing funduscopy were unavailability of ophthalmoscope (42.5\%) and lack of skills to detect signs of DR (40.2\%). Conclusion: This study found areas of weakness in the knowledge of GPs toward DR including risk factors, complications and screening guideline. Courses and training sessions are recommended as suitable remedial measures.
\end{abstract}

Keywords: Diabetic retinopathy, General practitioner, Screening guideline, Knowledge, Practice

\section{INTRODUCTION}

Diabetes mellitus (DM) is a common metabolic disorder and the number of diabetic patients is increasing. In 2015, Diabetes was responsible for 342,000 deaths in the Middle East and North Africa Region (MENA) and Saudi Arabia had the highest prevalence of $17.6 \%{ }^{[1]}$.

Diabetic retinopathy (DR) is a microvascular complication of diabetes that can affect the peripheral retina, the macula, or both; and is a leading cause of visual disability and blindness in people with diabetes. The severity of DR ranges from non-proliferative and preproliferative (moderate or severe nonproliferative) to more severely proliferative DR, in which the abnormal growth of new vessels occurs. The duration of diabetes is the most important risk factor. Other contributory risk factors include hypertension, poor glycemic control, obesity, tobacco use, insulin treatment, hyperlipidemia, pregnancy and Nephropathy ${ }^{[2]}$.

The global prevalence of DR among diabetic patients was $34.6 \%{ }^{[3]}$.In Saudi Arabia, several studies were conducted in variable regions to determine the prevalence of DR. The overall prevalence is $19.7 \%$ based on Saudi National Diabetes Registry (SNDR) ${ }^{[4]}$. The highest prevalence of DR was found in Taif province $(36.8 \%)^{[5]}$. whereas the least prevalence of DR was found in Riyadh region $(16.7 \%)^{[6]}$. Other regions with high prevalence were AlMadinah and Al-Hasa (36.1\% and 30\% respectively) ${ }^{[7,8]}$.

Tight control of blood pressure and blood sugar level are effective measures to reduce the risk of developing DR. A previous study showed that intensive glycemic control reduced the risk of developing retinopathy by $76 \%$ and slowed progression of retinopathy by $54 \%$ whereas controlled blood pressure had a 
$37 \%$ reduction in microvascular changes ${ }^{[9]}$. Advanced cases can be picked up and treated through Pan-retinal photocoagulation (PRP) which has been found to reduce the rate of vision loss in patients with proliferative diabetic retinopathy by $60 \%$, and focal laser surgery which has been found to decrease the rate of vision loss in individuals with macular edema by $50 \%^{[10]}$. General physicians (GPs) are the 1st line in management of diabetic patients in Saudi Arabia and the preventive methods against DR are primarily achieved by them. Consequently, it is very crucial to assess their knowledge and practice towards DR. However, there is paucity of data regarding this aspect in Saudi Arabia. Al Rasheed et al, assessed the knowledge and practice of physicians in primary health care centers of Riyadh city and found Multiple defective areas in screening guidelines, risk factors, screening tools and modalities of treatment regarding diabetes and diabetic retinopathy ${ }^{[11]}$. Similar results were reported by Khandekar et al who evaluated the knowledge, attitude and practice of physicians regarding retinal examination of diabetic patients in Oman and showed a limited knowledge and practice of eye care in diabetes ${ }^{[12]}$. Kraft et al assessed the primary care physicians' practice patterns for screening of DR in Indiana and significant difference from the published guidelines was found ${ }^{[10]}$. Moreover, studies were conducted in Ghana and Burundi and similar results were identified ,they concluded that GPs had very poor practice on screening for $\mathrm{DR}^{[9,13]}$.

There are some challenges that may prevent GPs from screening diabetic patients for DR. These challenges vary from a country to another. For instance, in KENYA Lack of equipment such as ophthalmoscope was the most common reason to hinder ocular examination followed by lack of skills ${ }^{[14]}$, whereas in south India, lack of time was found to be a barrier for screening diabetics by $\mathrm{GPs}^{[15]}$.

Knowledge, attitude and practice of general physicians towards diabetic retinopathy at the primary health care centers in Tabuk city, Saudi Arabia were not previously studied. Since the adequate knowledge and the wise physicians' practice will contribute to an early detection, management and subsequent prevention of vision loss due to DR; it would be beneficial to carry out this study aiming to determine their knowledge, attitude, and practice towards DR, and to identify the factors that affect their practice.

\section{MATERIALS AND METHODS}

We conducted a cross-sectional study. Eightyseven physicians were included by comprehensive sampling technique and they represent the general practitioners who work at primary health care units of Tabuk city- Saudi Arabia, from July to December 2017. Only the general practitioners were included, with exclusion of ophthalmologists or specialists in other medical fields. A validated selfadministered questionnaire was used for the data collection. It consists of 4 parts. The first section was about participants' demographics, the $2^{\text {nd }}$ section contained 14 questions about their knowledge, the $3^{\text {rd }}$ section had 5 questions about their attitude, and the $4^{\text {th }}$ section had 7 questions focused on physicians' practice and the factors that affect it. The collected data were coded and recorded into a spread sheet. The statistical analysis was performed by using the Statistical Package for the Social science (SPSS) version 20. Informed consents were obtained from the physicians before participation in this study.

\section{RESULTS}

Background characteristics

A total of 87 general physicians completed the questionnaire (a response rate of 100\%). The percentage of female physicians was higher than that of the males (58.6\% Vs $41.4 \%)$. More than half of the physicians (52.9\%) were from 31 to 40 year of age. Most physicians $(87.4 \%)$ were non-Saudi. The majority of physicians $(65.5 \%)$ had duration of practice from 1 to 10 years (Table1). 
Table 1. Demographic characteristics

\begin{tabular}{|c|c|c|}
\hline $\begin{array}{l}\text { Age } \\
25-30 \\
31-40 \\
41-50 \\
>50\end{array}$ & $\begin{array}{l}20 \\
46 \\
6 \\
15\end{array}$ & $\begin{array}{l}23 \\
52.9 \\
6.9 \\
17.2\end{array}$ \\
\hline $\begin{array}{l}\text { Gender } \\
\text { Male } \\
\text { Female }\end{array}$ & $\begin{array}{l}36 \\
51\end{array}$ & $\begin{array}{l}41.4 \\
58.6\end{array}$ \\
\hline $\begin{array}{l}\text { Nationality } \\
\text { Saudi } \\
\text { Non Saudi }\end{array}$ & $\begin{array}{l}11 \\
76\end{array}$ & $\begin{array}{c}12.6 \\
87.4\end{array}$ \\
\hline $\begin{array}{l}\text { Years of practice } \\
1-10 \text { years } \\
11-20 \text { years } \\
21-30 \text { years } \\
>30 \text { years }\end{array}$ & $\begin{array}{c}57 \\
15 \\
10 \\
5 \\
\end{array}$ & $\begin{array}{c}65.5 \\
17.2 \\
11.5 \\
5.7\end{array}$ \\
\hline
\end{tabular}

\section{Knowledge}

Almost all participants (94.3\%) were aware that eye could be affected by diabetes. Physicians' perceived factors that influence severity of diabetic retinopathy were duration of diabetes $(89.7 \%)$, glycemic control (89.7\%), hypertension $(70.1 \%)$, lipid profile $(44.8 \%)$, renal diseases $(39.1 \%)$, and pregnancy (24.1\%). Most of participants (83.9\%) knew that retinal vascular disease can be seen in patients with diabetes. However, a defect was detected in their knowledge concerning complications of diabetic retinopathy such as retinal detachment $(43.7 \%)$ and vitreous hemorrhage (28.7\%). Another weakness was noticed in following the diabetic screening guidelines of type 1 diabetes, Nearly half (47.1\%) of physicians were found to mistakenly refer type 1 diabetic patients immediately after the diagnosis. Only $27.6 \%$ of them referred the patients with type 1 diabetes to an ophthalmologist as per the guideline. The responses to questions about screening and follow up of type 1 and 2 diabetes are given in (table 2).

Table 2. Screening and follow up of type 1 and 2 diabetes

\begin{tabular}{|l|l|l|}
\hline Variable & $\begin{array}{l}\text { Type 1 } \\
\mathrm{n}(\%)\end{array}$ & $\begin{array}{l}\text { Type 2 } \\
\mathrm{n}(\%)\end{array}$ \\
\hline $\begin{array}{l}\text { Should visit an ophthalmologist } \\
\text { following diagnosis }\end{array}$ & $\begin{array}{l}\text { Yes 82 (94.3\%) } \\
\text { No 5 (5.7\%) }\end{array}$ & \\
\hline $\begin{array}{l}\text { Duration after diagnosis } \\
\text { Immediately: }\end{array}$ & $\begin{array}{l}\text { Y (47.1\%) } \\
1 \text { year }\end{array}$ & $69(79.3 \%)$ \\
2 years & $2(2.3 \%)$ & $8(9.2 \%)$ \\
5 years & $24(27.6 \%)$ & $2(2.3 \%)$ \\
Others & $4(4.6 \%)$ & $5(5.7 \%)$ \\
\hline Should visit an ophthalmologist & Yes 84(96.6\%) & $3(3.4 \%)$ \\
regularly & No 3(3.4\%) & Yes 86 (98.9\%) \\
\hline $\begin{array}{l}\text { Frequency of regular follow up: } \\
\text { Every year }\end{array}$ & No 1(1.1\%) \\
Every 2 years & $64(73.6 \%)$ & \\
Every 5 years & $7(8 \%)$ & $70(80.5 \%)$ \\
Others & $11(12.6 \%)$ & $8(9.2 \%)$ \\
& $5(5.7 \%)$ & $7(8 \%)$ \\
\hline
\end{tabular}

Only $(10.3 \%)$ of physicians agreed on digital fundus photography as an ideal method for detecting diabetic retinopathy, whereas over half of participants $(55.2 \%)$ considered direct ophthalmoscope instead. About a quarter of the participants $(25.3 \%)$ chose fluorescein angiography and (9.2\%) chose slit lamp biomicroscopy. 


\section{Attitude}

The responses to questions about attitudes of GPs toward DR are given in (Table 3). The majority of the GPs showed a positive attitude regarding DR, $79(90.8 \%)$ of them disagreed that eye examination is only required in Table 3. Attitude of GPs towards DR.

\begin{tabular}{|c|c|c|c|}
\hline Variable & $\begin{array}{l}\text { Agree } \\
\text { n }(\%)\end{array}$ & $\begin{array}{l}\text { Disagree } \\
\mathrm{n}(\%)\end{array}$ & $\begin{array}{l}\text { I don't know } \\
\mathrm{n}(\%)\end{array}$ \\
\hline $\begin{array}{l}\text { Eye examination is only } \\
\text { required in diabetic } \\
\text { patients when vision is } \\
\text { affected }\end{array}$ & $7(8 \%)$ & $79(90.8 \%)$ & $1(1.1 \%)$ \\
\hline $\begin{array}{l}\text { Newly detected diabetic } \\
\text { patients do not require eye } \\
\text { checkups }\end{array}$ & $4(4.6 \%)$ & $82(94.3 \%)$ & $1(1.1 \%)$ \\
\hline $\begin{array}{l}\text { hypertension control is } \\
\text { essential for preventing } \\
\text { vision loss in diabetic } \\
\text { retinopathy }\end{array}$ & $82(94.3 \%)$ & $5(5.7 \%)$ & \\
\hline $\begin{array}{l}\text { good lipid profile is } \\
\text { essential for preventing } \\
\text { vision loss in diabetic } \\
\text { retinopathy }\end{array}$ & $71(81.6 \%)$ & $10(11.5 \%)$ & $6(6.9 \%)$ \\
\hline $\begin{array}{l}\text { fundus examination } \\
\text { should be done by } \\
\text { ophthalmologist only }\end{array}$ & $31(35.6 \%)$ & $53(60.9 \%)$ & $3(3.4 \%)$ \\
\hline
\end{tabular}

\section{Practice}

The vast majority $(93.1 \%)$ of GPs counseled diabetic patients to control their blood glucose level, blood pressure, and lipid profile. Over half of them $(58.6 \%)$ never advised retinal examination for pregnant diabetic women whereas (17.2\%) of GPs advised diabetic women to have their fundus examined preconceptionally. Only (9.2\%) of GPs were found to correctly advise retinal examination in $1^{\text {st }}$ trimester. Other physicians advised fundoscopy in $2^{\text {nd }}$ trimester $(5.7 \%)$ and $3^{\text {rd }}$ trimester $(9.2 \%)$. The majority $(87.4 \%)$ of GPs refer their diabetic patients annually for follow up and $(5.7 \%)$ of them refer their diabetic patients every 2 years. Fundus examination for diabetic patients was performed by over half of GPs $(56.3 \%)$ and about one third of GPs (34.5\%) never perform fundus examination for diabetic patients. Those who examined the retina of diabetic patients only when they had an eye compliant were $(9.2 \%)$.

Challenges proposed by the GPs that may prevent them from doing fundoscopy for diabetic patients were unavailability of ophthalmoscope (42.5\%), lack skills of using diabetic patients when vision is affected. However, approximately third of GPs 31 $(35.6 \%)$ were on the opinion that fundus examination should be performed only by an ophthalmologist. 
of awareness among nearly half of GPs on the serious ophthalmic complications of diabetes such as vitreous hemorrhage ${ }^{[16]}$. Although antenatal care is principally provided by GPs at primary health care centers of Saudi Arabia, less than quarter of GPs were able to identify pregnancy as a risk factor, and this is fewer than what was reported by Oenga in Kenya ${ }^{[14]}$. This might be attributed to their lack of specialization and subsequent defect in providing optimal health care. Therefore, GPs should be notified about this issue through continuous medical education. Low percentage of GPs knew the screening guideline for type 1 diabetes, as compared to those for type 2 diabetes. This difference in the knowledge could be due to the fact that type 2 diabetic patients frequently seen by them, as type 1 diabetic patients are mostly followed up by the endocrinologists. Similar findings were published from Riyadh city ${ }^{[11]}$. More than half of GPs never advice retinal examination for pregnant diabetic women during their practice and this could be explained by their inability to identify pregnancy as a risk factor for developing DR. consequently, screening guidelines for diabetic pregnant women should be incorporated in their practice. More than half of GPs claimed that they performed fundus examination for diabetic patients. However, this percentage could be higher if ophthalmoscopes are well provided. Indeed, approximately half of physicians who performed funduscopy were not able to identify signs of DR. In a study conducted by Niyonsavye in Burundi, a higher proportion $(80 \%)$ of GPs were not able to appreciate details of retina during funduscopy. For that reason, efforts should be directed initially towards enhancing their knowledge about risk factors, complication and referral as per guidelines. After promoting their knowledge, they can be offered training sessions to improve their skills in fundus examination as initial screeners. Screening for DR by GPs carries a risk of missing retinopathy cases (false negative) ${ }^{[17]}$. However, it was reported that trained GPs achieved an acceptable detection rate $(>87 \%)$ for diabetic retinopathy ${ }^{[18]}$.

\section{Limitations}

A major limitation of this study is the nature of the self-reporting questionnaires that could be associated with response bias. It is worth nothing that our study results reflect the knowledge, attitude and practice of GPs in Tabuk city and should not be generalized to all primary care physicians of Saudi Arabia.

\section{CONCLUSION}

AND

\section{RECOMMENDATIONS}

This study found areas of weakness in the knowledge of GPs toward DR including risk factors, complication and follow up of the screening guideline. General physicians showed a positive attitude toward DR. The lack of ophthalmoscope and skills are the most common barriers against retinal examination by GPs. Educational sessions and workshops are highly recommended to improve Knowledge of GPs toward DR. Ophthalmoscopes should be accessible and training sessions should be provided by expert ophthalmologists to improve skills of the GPs.

\section{References:}

1. International Diabetes Federation(2017): IDF Diabetes Atlas, 8th edn. Brussels, Belgiu. http://www.diabetesatlas.org. 2. Cad W (2008): Diabetes-related microvascular and macrovascular diseases in the physical therapy setting. Physical therapy, $\mathbf{8 8}(11)$ : 1322-1335.

3. Ya J (2012): Global prevalence and major risk factors of diabetic retinopathy. Diabetes care, 35(3): 556-564.

4. Al-Rubeaan $K$ et al.(2015): Diabetic retinopathy and its risk factors in a society with a type 2 diabetes epidemic: a Saudi National Diabetes Registry-based study. Acta ophthalmologica, 93(2:) e140-e147.

5. Al Ghamdi A et al. (2012): Rapid assessment of avoidable blindness and diabetic retinopathy in Taif, Saudi Arabia. British Journal of Ophthalmology, 96(9): 1168-1172 
6. Alwakeel J et al. (2008): Diabetes complications in 1952 type 2 diabetes mellitus patients managed in a single institution. Annals of Saudi medicine, 28(4): 260

7. El-Bab M et al. (2012): Retinopathy and risk factors in diabetic patients from Al-Madinah AlMunawarah in the Kingdom of Saudi Arabia. Clinical Ophthalmology (Auckland, NZ), 6(1): 269-276

8. Khan A et al. (2010): Prevalence and determinants of diabetic retinopathy in Al Hasa region of Saudi Arabia: primary health care centre based cross-sectional survey, 20072009. Middle East African journal of ophthalmology, 17(3): 257

9. Mensah V et al. (2013): Knowledge, attitudes and practices of diabetic retinopathy among medical officers in the regional Hospital of Ghana,Doctoral dissertation, Faculty of Medicine, Department of Ophthalmology University of Nairobi.

10. Kraf S et al. (1996): Primary care physicians' practice patterns and diabetic retinopathy. Current levels of care. Archives of family medicine, 6(1): 29-37

11. Al Rasheed $\mathrm{R}$ et al. (2017): Diabetic retinopathy: Knowledge, awareness and practices of physicians in primary-care centers in Riyadh, Saudi Arabia. Saudi Journal of Ophthalmology, 31(1): 2-6.

12. Khandekar $\mathbf{R}$ et al. (2008): Retinal examination of diabetic patients: knowledge, attitudes and practices of physicians in
Oman.Eastern Mediterranean Health Journal, 14:4.

13. Niyonsavye L (2015):

Knowledge, attitudes and practices on diabetic retinopathy among general practitioners in district and regional hospitals in the north region of Burundi, Sc Thesis in Ophthalmology to University of Nairob.

14. Oenga $R$ ( 2012): Diabetic retinopathy; knowledge, attitudes and practice among general practitioners in provincial hospitals in Kenya, erepository.uonbi.ac.ke/bitstream/hand le/11295/8342/abstract.pdf?sequence= 1.

15. Namperumalsamy $P$ (2006): An inexpensive tool for routine fundus examination at primary eye care centres. Community Eye Health, 19(57): 13.

16. Muecke $\mathbf{J}$ et al. ( 2008): Awareness of diabetic eye disease among general practitioners and diabetic patients in Yangon, Myanmar. Clinical \& experimental ophthalmology, 36(3): 265-273

17.Reenders $\mathrm{K}$ et al. (1992): Screening for diabetic retinopathy by general practitioners .Scandinavian journal of primary health care, 10(4): 306-309

18. Owens D et al.(1998): Screening for diabetic retinopathy by general practitioners: ophthalmoscopy or retinal photography as $35 \mathrm{~mm}$ colour transparencies? Diabetic medicine, 15(2): 170-175 